\title{
MODERN APPROACHES REGARDING CLASSIFICATION AND TERMINOLOGY OF FIREARMS UP TO 20MM IN CALIBER
}

\author{
Florin ILIE, Dănuț-Eugeniu MOȘTEANU, Bogdan-Mihai GEORGESCU \\ "Nicolae Bălcescu" Land Forces Academy, Sibiu, Romania \\ ilieflorinv@yahoo.com, dmosteanu@gmail.com, bogdan.502.xt@gmail.com
}

\begin{abstract}
One would outright tell the differences between a rifle and a machine gun. But what if the things get so much complicated so that only a minuscule detail becomes the key into telling if that piece of ordnance pertains to a specific category of arms, more precisely if it fits into a distinguished subcategory of armament. At the moment, there are indefinitely many ways of structuring firearms into certain categories, but the methods are vague and imprecise when it comes to types that are strongly related or similar. Thus, combining history records and the official texts of various institutions ensue a more complex and plausible method of firearms classification and terminology registering alike.
\end{abstract}

Keywords: firearm, small arm, light weapon, rifle, machine gun

\begin{tabular}{|c|c|}
\hline $\begin{array}{l}\text { 1. Preliminary Terminology and } \\
\text { Definitions } \\
\text { Small arms are to be used individually and } \\
\text { light weapons are designated as crew- } \\
\text { served ordnance, while both of them are } \\
\text { man-portable (figure 1). Described as such, } \\
\text { they are systems of armament used by } \\
\text { armed forces. Small arms can occasionally } \\
\text { be met in infantry regulations as light } \\
\text { infantry weapons, whereas light weapons as } \\
\text { heavy infantry weapons. Cartridges are } \\
\text { used by both classes, restricted to } 20 \text { mm, } \\
\text { but grenades, rockets, missiles and } \\
\text { projectiles are used too by some types of }\end{array}$ & $\begin{array}{l}\text { the other hand, each country has its own } \\
\text { regulations regarding civilian usage of } \\
\text { armament and it is universally accepted that } \\
\text { a firearm means small arms and cartridge- } \\
\text { based light weapons. The same } 20 \text { mm in } \\
\text { caliber restriction applies too, but the } \\
\text { aspects of portability and utilization as } \\
\text { purpose are not taken into consideration [1]. } \\
\text { Further on, one last class of armament can } \\
\text { be described which is not included in the } \\
\text { UN regulations. Since it is not relevant to } \\
\text { this study, it will only be mentioned as } \\
\text { heavy non-portable weapons covering } \\
\text { artillery-like pieces, anti-aircraft and } \\
\text { vehicle mounts, naval guns, etc. [4]. }\end{array}$ \\
\hline
\end{tabular}



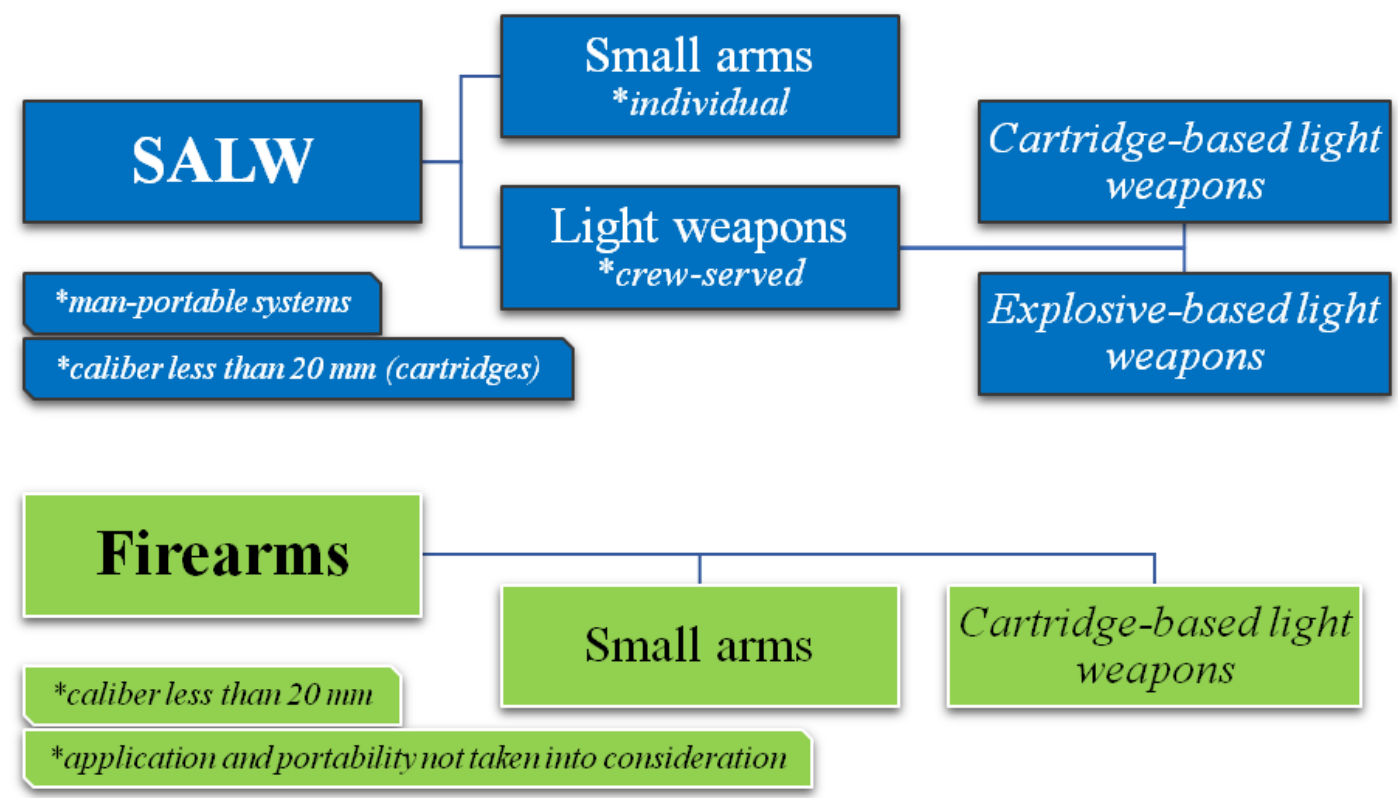

Figure 1: Small arms and Light weapons distribution, military (upper blue scheme) and civilian (lower green scheme) circumstances

\section{Firearms Structuring Stages}

Diving deeper into more precise details about firearms, the complexity of classification increases. Once a firearm has been designated as whether a small arm or a light weapon, the next stage will require sorting it as either a handgun or a long gun. The simplest distinction that confirms the belonging group states that a firearm is a handgun if it was designed to be fired from one hand, not taking into consideration the use of the second hand for recoil damping. Otherwise, that piece of ordnance is a long gun [5].

The subsequent step will require to identify the type of barrel by the presence of rifling. A rifled barrel will contain lands and grooves, whereas a smooth-bore barrel will not. Categories full of rifled barrel firearms can be found especially across the military armament, but also special cases where a firearm may use combined types of barrels on civilian market [3].

The analysis continues by indicating the main type of gun action by its behavior after taking a shot. A manually-operated firearm refers to the case when the shooter is required to operate the action after every shot. The types of firearms that fall under this specific requirement are also called repeating firearms. A self-loading firearm is used when addressing the firearms that self-reload after each pressing of trigger. Within this group there are mainly two types of firearms, semi-automatic and fullautomatic [3].

The fifth and the last stage into identifying and classifying a firearm will address the whole nature of it, structuring all of them on certain categories and subcategories by merging aspects of the steps mentioned above. This represents the most demanding process and also the most relevant to the actual study. As for every domain, there are outliers and troublesome items that may divert the whole process to an inconclusive result. The main reasons are based on lack of information, proprietary manufacturing or peculiar designs of firearms.

For structuring a set of firearms on specific categories, there has to be taken into consideration certain historical limitations as well and not just the physical characteristics of a gun. The historical avenues will add up a new requirement: the way it was designed and designated to be used on the battlefield based on the conflict era. Their evolution can be developed around the manufacturing patterns of firearms industry and the functionality it 
had in relation to both world wars and present day. This way, the classification can be organized on four historical stages, as described in the introduction of the study (figure 2).

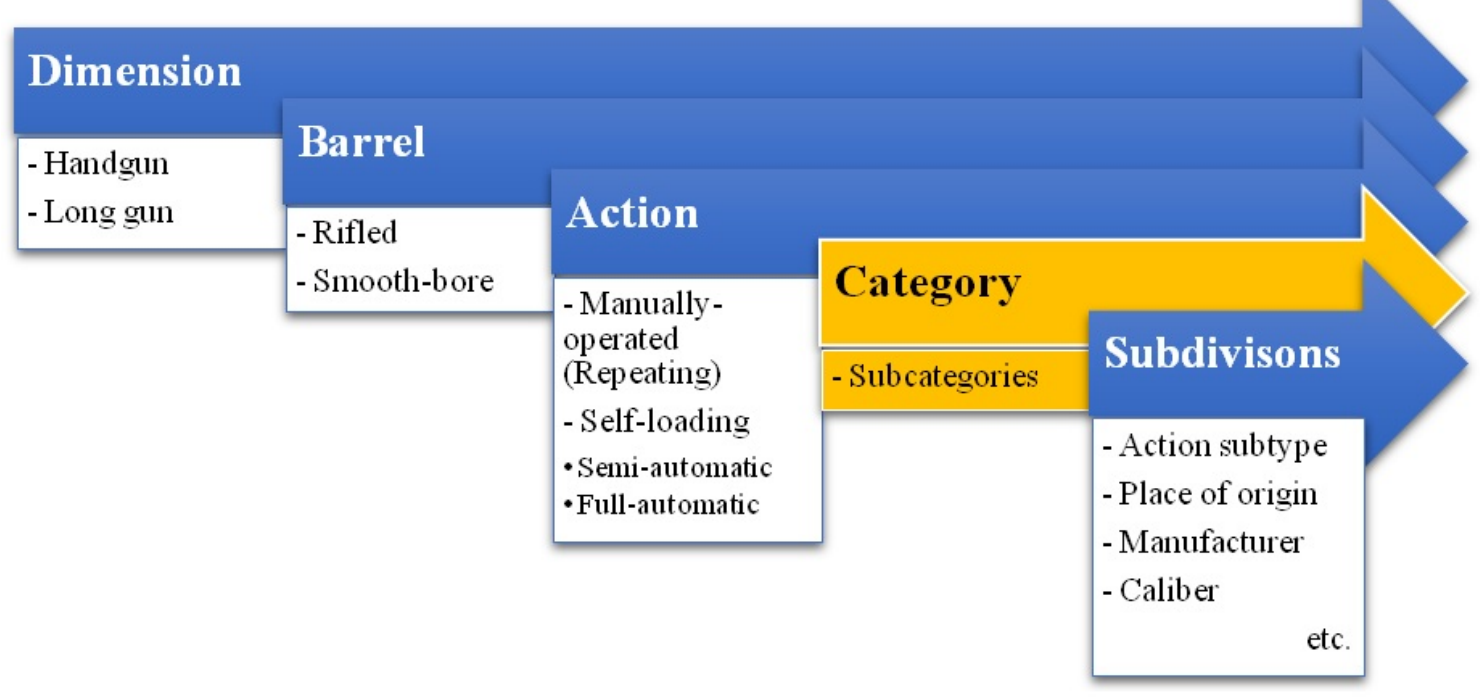

Figure 2. Stages of a firearm classification within SALW combined class of armament

As mentioned above, structuring firearms on categories and subcategories represents the ending phase of the analysis, but it may also proceed with linking the respective piece of ordnance to particular subdivisions. This may include criteria like subtypes of gun actions, country of origin, manufacturer, caliber, etc. [1].

\section{Categories and Subcategories of} Firearms

A principle to approach in this case is the principle of intersection which states that the subcategories that fall under the main categories overlap with the other stages of classification (table 1). However, they can be arranged in such a way to be independent, but not to a full scale which is the aim of this part of the study. Both groups of categories classification can be accepted when researching and studying firearms but the level of accuracy is determined by the user need-to-know criteria.

Table 1 Simplified version of firearms categories classification [3] Handguns

\begin{tabular}{|c|c|c|c|}
\hline \multicolumn{4}{|c|}{ Handguns } \\
\hline & Rifled & & Smooth-bore \\
\hline Self-loading pistols & Revolvers & *Other rifled handguns & *Smooth-bore handguns \\
\hline
\end{tabular}

\begin{tabular}{|c|c|c|c|c|c|c|c|}
\hline \multicolumn{8}{|c|}{ Long guns } \\
\hline \multicolumn{5}{|c|}{ Rifled } & \multicolumn{3}{|c|}{ Smooth-bore } \\
\hline $\begin{array}{c}\text { Sub- } \\
\text { machine } \\
\text { guns }\end{array}$ & $\begin{array}{l}\text { Machine } \\
\text { guns }\end{array}$ & $\begin{array}{l}\text { Self- } \\
\text { loading } \\
\text { rifles }\end{array}$ & $\begin{array}{l}\text { Manually- } \\
\text { operated } \\
\text { rifles }\end{array}$ & $\begin{array}{l}{ }^{*} \text { Other } \\
\text { rifled } \\
\text { long } \\
\text { guns }\end{array}$ & $\begin{array}{c}\text { Self- } \\
\text { loading } \\
\text { shotguns }\end{array}$ & $\begin{array}{c}\text { Manually- } \\
\text { operated } \\
\text { shotguns }\end{array}$ & $\begin{array}{l}\text { *Other } \\
\text { smooth- } \\
\text { bore long } \\
\text { guns }\end{array}$ \\
\hline
\end{tabular}


The second variant of classification is nothing more but an extended version of the first one. It can be observed that the third classification row can be further expanded with rows of subcategories, thus making it more detailed. In this case, the main categories have been colored in red, therefore it can be seen how the categories intersect with the classification stages. Furthermore, the extended variant lacks the presence of 'other types of guns' which came in the last table as a completion with other peculiar and rare sources of ordnance, such as handcrafted guns, special purpose guns, manually-operated handguns, one-shot smooth-bore handguns, etc. (table 2) [3].

For every each one of the categories there will always be some outliers that may represent a different subcategory or may come as a discrepancy, different generations for a specific subcategory and carbine versions likewise. A further analysis will also take into account the possibility of structuring a subcategory of firearms based on their action type and also on different parts that define its particular characteristics as a subcategory.

Table 2 Extended version of firearms categories classification

\begin{tabular}{|c|c|c|}
\hline \multicolumn{3}{|c|}{ Rifled } \\
\hline \multicolumn{2}{|c|}{ Self-loading pistols } & Revolvers \\
\hline Semi-automatic pistol & Machine pistol (MP) & - \\
\hline
\end{tabular}

\section{Long guns}

Rifled

\begin{tabular}{|c|c|c|c|c|c|c|}
\hline \multicolumn{7}{|c|}{ Rifles } \\
\hline \multicolumn{4}{|c|}{ Self-loading rifles } & \multicolumn{2}{|c|}{ Manually-operated rifles } & $\begin{array}{l}\text { Anti-materiel } \\
\text { rifle (AMR) }\end{array}$ \\
\hline $\begin{array}{l}\text { Semi- } \\
\text { automatic } \\
\text { rifle }\end{array}$ & $\begin{array}{l}\text { Assault } \\
\text { rifle }\end{array}$ & $\begin{array}{l}\text { Battle } \\
\text { rifle }\end{array}$ & $\begin{array}{c}\text { Designated } \\
\text { marksman } \\
\text { rifle } \\
(\mathrm{DMR})\end{array}$ & $\begin{array}{l}\text { Repeating } \\
\text { rifle }\end{array}$ & Sniper rifle & - \\
\hline
\end{tabular}

\section{Machine Guns}

\begin{tabular}{|c|c|c|c|c|c|c|}
\hline $\begin{array}{l}\text { Submachine } \\
\text { gun }(\mathrm{SMG})\end{array}$ & $\begin{array}{c}\text { Squad } \\
\text { automatic } \\
\text { weapon } \\
\text { (SAW) }\end{array}$ & $\begin{array}{l}\text { Automatic } \\
\text { rifle }\end{array}$ & $\begin{array}{c}\text { Light } \\
\text { machine } \\
\text { gun (LMG) }\end{array}$ & $\begin{array}{l}\text { General } \\
\text { purpose } \\
\text { machine } \\
\text { gun } \\
\text { (GPMG) }\end{array}$ & $\begin{array}{l}\text { Medium } \\
\text { machine gun } \\
(\mathrm{MMG})\end{array}$ & $\begin{array}{c}\text { Heavy } \\
\text { machine } \\
\text { gun } \\
(\mathrm{HMG})\end{array}$ \\
\hline
\end{tabular}

\section{Smooth-bore}

\section{Shotguns}

Self-loading shotguns

Manually-operated shotguns

Semi-automatic shotgun Full-automatic shotgun 


\section{Handguns}

Semi-automatic pistols are divided by their trigger action, more precisely traditional double-action (TDA) (also called singleaction/double-action (SA/DA) or reversed) and double-action only (DAO) (also encountered as simply double-action). In a traditional double-action, the user has access and can manually-operate the hammer even though it is not required, thus combining the ability of a gun to fire both in single-action and double-action as well. As for double-action only, the hammer is found inside the frame ('hammerless', as it is sometimes called), it is not exposed outside the gun so the user cannot cock it manually at his wish. Hence, the visual difference between the two is based whether the gun's hammer is visible or not to the outside of the frame, behind the slide [5].

Machine pistols (MP) do not benefit of any subclassification like their semi-automatic counterpart, but they can be met in a carbine variant too. Both types of self-loading pistols may come with an additional stock and other possible attachments, that can be mounted to the gun, therefore transforming it into a carbine. The only objection here is that this type of carbine does not comply to the basic definition as it only covers the fact that it renders the gun a little longer to a carbine's dimension. The same applies in the case of a modern 'carbine conversion kit' which only converts the handgun by mounting it into a metallic frame or assembly in order to improve its accuracy and handling. Moreover, self-loading pistols can be found in another variation that takes into consideration the hammer design, a pistol being either hammer-fired or striker-fired. The striker-fired ones are true 'hammerless' since the hammer is missing and the main spring is acting directly on the firing pin, a variation that can be found on the newest designs of double-action only semi-automatic pistols. On the other hand, a hammer-fired type has its sequence of fire realized after the hammer interacts with the firing pin, driving it into the cartridge primer [1].

\section{Rifles}

Semi-automatic and repeating rifles refer to everything that has to do with civilian ordnance whether they come with attachments like scopes and bipods or if they are built in a carbine variant. They can also be used in relation with the old service rifles of both world wars. Those rifles come in three different versions: full length (total length between $760-810 \mathrm{~mm}$ ), universal short (total length between 610-660 $\mathrm{mm}$ ) and carbines (total length between 430-510 $\mathrm{mm}$ ). A carbine, in general, can either be a short version of a rifle or a smaller caliber version of a rifle, used in both civilian and military contexts [3].

Designated marksman and sniper rifles are military type-only of guns when using such terminology. In principle, a DMR will always be semi-automatic with a detachable box magazine designated to be used at a platoon level to engage targets not further than 800-1000 m. It may however evolve from a battle rifle or be a stand-alone model. Sniper rifles are usually bolt-action with an integral box magazine with reduced capacity used by special trained snipers that work in a team with a spotter to engage targets at long distances with more precision. A sniper rifle is also capable to use more powerful cartridges, such as those with $8.6 \mathrm{~mm}$ in caliber. The biggest misconception between them is that a sniper rifle can also be semi-automatic, depending on the respective army table of organization and equipment, but it can as well be an anti-materiel rifle used by case. Therefore, both terms are relative to how they are actually distributed by armies and used on the battlefield by their operators.

Anti-materiel rifles have been manufactured across the years both in semi-automatic and repeating actions, hence, they could not be cataloged in one of the latter categories. They are a special type of rifles primarily used by snipers either to engage targets at long-range or behind soft armor or to use against military equipment. Their history is that they evolved from the now obsolete anti- 
tank rifles used in the last century against enemy armored trucks and tanks. Their caliber is the largest to be found for the infantry that does not exceed the $20 \mathrm{~mm}$ gap between light and heavy weapons, although there are anti-material rifles developed in 20 $\mathrm{mm}$ caliber, but they are rather called 'cannons' instead of 'rifles' [1].

The last but not the least, the assault and battle rifles were and are standard army rifles used since the Second World War up to today. An assault rifle must be capable of selective fire, to use intermediate cartridges via detachable box magazines and to have an effective range of at least $300 \mathrm{~m}$. They have carbine versions as mentioned some paragraphs above and a civilian variant of an assault rifle is often called assault weapon. In contrast, a battle rifle is more powerful using rifle-caliber cartridges thus attaining longer effective ranges, but their selective fire capability is not a must anymore. They were used as standard rifles only during the Cold War Era as they were gradually phased out by the more maneuverable assault rifle. There are instances in which an old war semiautomatic rifle may be called a battle rifle only for its specifications, the misconception here being the fact that its period of usage has been wrongly admitted [2].

\section{Machine Guns}

Sub-machine guns were first developed during WWI, gradually evolving through the last century. They can be structured on three main generations, more precisely the First World War and Interwar period as the first generation, the Second World War and Postwar period as the second generation and the modern-day period as the third generation. One particular subcategory of SMGs is known as Personal defense weapon $(P D W)$, is included in the third generation and is divided in two types: with armor-piercing capability and as a holsterable SMG not intended for front-line combat (bigger than pistols, smaller than SMGs, but not a machine pistol) [2].

Even though the entire machine guns category of arms can be composed of (not taking into account the SMGs) only the light, medium and heavy ones, there are outliers that may form other different subcategories [3]:

- Squad automatic weapon: intermediate caliber, magazine and belt fed, bipod fired;

- Automatic rifle: rifle caliber, magazine fed with limited capacity, shoulder or hip fired, minimal sustained fire capacity;

- Light machine gun: rifle caliber, belt fed (magazine in certain instances), bipod fired;

- General purpose machine gun: rifle caliber, belt fed, bipod and tripod fired, quick-change barrel;

- Medium machine gun: rifle caliber, belt fed, tripod fired, air cooled;

- Heavy machine gun: rifle caliber, belt fed, tripod fired, water cooled, minimal portability, later evolved into large caliber, air cooled heavy machine guns.

\section{Shotguns}

Firstly, shotgun barrels can be full length or can be sawn-off which dictate the gun's overall dimension. Even though a sawn-off shotgun is still a debatable subject nowadays whether it is to be categorized as a handgun or as a long gun based on its dimension, a sawn-off shotgun is still a shotgun after all. Secondly, they may come in different numbers, one (often named as single-shot shotgun), two (double-barreled shotgun) or more (rare and peculiar occasions), or even combined (smooth-bore and rifled barrels together, but the gun is still considered a shotgun). Lastly, a shotgun can have its barrels positioned in two ways, side-by-side and over-under (when considering a double-barreled shotgun) [5]. The latter two instances are only applied to the shotguns which have a break-action/open (breech-loaded) type of action and all cases of barrels types are together analyzed only for manuallyoperated shotguns.

Shotguns borrow the rifles' action types in the exact same manner with little to no 
difference. The self-loading shotguns are either semi-automatic or full-automatic, just like their rifled counterparts. A manuallyoperated shotgun, on the other hand, may come down with variations regarding its action type, but with some principles of operation developed for rifles too, boltaction and lever-action to be precise. There are also two action types used only for shotguns, break-action/open (breechloaded) and pump-action (slide-action), the latter being the last one to be developed and massively used today and also the most unique in terms of shotguns [5]. Breechloaded shotguns may be considered an equal with the rifles that are loaded through their breech part of the barrel. There are instances when history retained examples of revolving shotguns, the first models being developed around the middle of XIX century, their production continuing even nowadays.

Usually, law enforcement has at its disposal riot shotguns, also named defensive shotguns, whereas armies make use of combat shotguns. There is no straight line that can divide the two terms. A riot shotgun can have a usage by military personnel and law enforcement in door breaching applications and riot control, and civilians too as a home defense weapon. A combat shotgun is typically used by armies either as an offensive gun or as a door breaching weapon. Characteristically speaking, a riot shotgun has a shorter barrel between 14 to 20 inches, reduced magazine capacity and it is considered less effective in range compared to a combat shotgun that is made to be effective at around $70 \mathrm{~m}$ or more depending on the pellet size, with its longer barrel, at around 20 inches, and a higher capacity magazine. Both are usually encountered nowadays in 12-gauge caliber. Door breaching shells can be used in both military and law enforcement contexts, in the latter less lethal shells being used too. A unique aspect for a combat shotgun is based on its capability of mounting bayonets, hence its name as 'trench shotgun' used during World War I [1].

\section{Conclusions}

Classifying ordnance has always been a troublesome operation as it does not rely on fixed definitions. Even if UN offer us some starting points regarding firearms, small arms and light weapons, there are still many gaps to fill along the way.

The actual study has its main aim into taking those offered and completing them with a full classification up the way to subcategories of armament. Stages of classification have been followed through this process, thus establishing a guideline for persons which show interest not only for understanding how firearms have been manufactured across the years, but also for professionals and historians who are studying them.

All technical papers would not be complete without any historical reference. Firearms history stretches for almost a millennium, but only starting with the Industrial Revolution they started to become more diverse and complex. Both world wars and the years that followed developed new ways and tactics of waging war, directly influencing the firearms industry. Not considering such steps would only result in failure for a detailed classification.

\section{References List}

[1] Ilie, F., Trocan, C., - Arme Mici (Small Arms) în Armatele Moderne, Editura Academiei Forţelor Terestre „Nicolae Bălcescu”, Sibiu, 2017.

[2] Popenker, M. \& Williams A.G. (2012). Sub-machine Gun: The Development of submachine guns and their ammunition from World War I to the present day. Ramsbury: The Crowood Press.

[3] Small Arms Survey. (2018). An Introductory Guide to the Identification of Small Arms, Light Weapons, and Associated Ammunition, pp. 28-81. Geneva: Graduate Institute of International and Development Studies. 
[4] United Nations. (2005). International Instrument to Enable States to Identify and Trace, in a Timely and Reliable Manner, Illicit Small Arms and Light Weapons, A/CONF.192/15, pp. 2-3.

[5] Walker, R.E. (2013). Cartridges and firearms identification. New York City: CRC Press. 